\title{
Pushover Analysis of R.C. Frame Building with Shear Wall
}

\author{
Nitin Choudhary ${ }^{1}$ Prof. Mahendra Wadia ${ }^{2}$ \\ Research scholar, ${ }^{l}$ Department of civil engineering, Alpine Institute of Technology, Ujjain \\ Asst. Professor, ${ }^{2}$ Department of civil engineering, Alpine Institute of Technology, Ujjain
}

\begin{abstract}
A performance - based design is at controlling the structural damage based on precise estimation of proper response parameter. In performance based seismic analysis evaluates how building is likely to perform. It is an iterative process with selection of performance objective followed by development of preliminary design, an assessment whether or not the design meets the performance objective; In the present study pushover analysis has been done an two multistoried R.C. frame building; In which plan of one building was taken symmetrical and it consist of 2 bay of $5 m$ in $x$ direction \& 2 bay of $4 m$ in y direction and second building having $L$ shaped unsymmetrical plan. The shear wall is providing for studying their resisting lateral forces. In this paper highlight the effect of shear wall on R.C frame building when shear wall providing along the longer and shorter side of the building. The base shear and displacement will decreases of building. The comparative study has been done for base shear, story drift, spectral acceleration, spectral displacement, story displacement.
\end{abstract}

Key word: Pushover analysis, Capacity spectrum method, shear wall

\section{Introduction}

The Concept of seismic design is to provide building structure with sufficient strength and deformation capacity to sustain seismic demands imposed by ground motion with adequate margin of safety. Even if the probability of occurrence of earthquake within the life span of structures is very less, strong ground motion would generally cause greater damage to the structure. For designing the structures for this combination having less probability and extreme loading, a criterion is adopted in such a way that a major earthquake, with a relatively low probability of occurrence is expected to cause significant damage which may not be repairable but not associated with loss of life Performance based seismic design is gaining popularity from last decades. Many countries are separate document over this method such as FEMA, ATC etc. Recently formulated Euro codes EC2 and EC8 [Euro code 2, Euro code 8] are also based on performance based design philosophy. But Indian codes are still silent over this method. Even the IS 1893(part I): 2007 draft doesn't talk about performance based seismic design

\section{Objectives}

1) To study the effect of providing shear walls, in RC framed building, using pushover analysis.

2) To compare the seismic response of building in terms of base shear, storey drift, spectral acceleration, spectral displacement and storey displacements.

3) Determination of performance point of building.

4) To determine the best possible combination of reinforcement that would be both economical and effective. The resultant roof displacement is then compared with target displacement. If it is lower then, the design is known as performance based design.

\section{Literature Review}

J. B. Mander (2001) reviewed from an historical perspective past and current developments in earthquake engineered structures. Based on the present state-of-the-practice in New Zealand, and a world-view of the stateof-the-art, he argued that in order to make progress towards the building of seismic resilient communities, research and development activities should focus on performance-based design which gives the engineer the ability to inform clients/owners of the expected degree of damage to enable a better management of seismic risk. To achieve expected performance outcomes it will be necessary to supplement, current force-based design standards with displacement-based design methodologies.

Qiang Xue, et al (2003) presented a performance-based seismic design procedure, which is directly associated with pre-quantified performance criteria, by employing a displacement-based approach. A lower bound of yielding displacement of the structure to satisfy these performance criteria was proposed.

Andreas J. Kappos et al (2004) proposed a performance-based design procedure for realistic 3D reinforced concrete $(\mathrm{R} / \mathrm{C})$ buildings, which involves the use of advanced analytical tools. The proposed method was then applied to a regular multistory reinforced concrete 3D frame building and was found to lead to better seismic performance than the standard code (Eurocode 8) procedure, and in addition led to a more economic design of 
transverse reinforcement in the members that develop very little inelastic behavior even for very strong earthquakes.

X.-K. Zou et al (2005) present an effective computer-based technique that incorporates pushover analysis together with numerical optimization procedures to automate the pushover drift performance design of reinforced concrete (RC) buildings. Performance-based design using nonlinear pushover analysis, is a highly iterative process needed to meet designer-specified and code requirements.

Qiang Xue, Chia-Wei Wu et al (2007) summarized the development of the seismic design draft code for buildings in Taiwan using performance-based seismic design methodology and case studied following the guidelines.

R. K. Goel and A. K. Chopra presented an improved Direct Displacement-Based Design Procedure for Performance-Based seismic design of structures. Direct displacement-based design requires a simplified procedure to estimate the seismic deformation of an inelastic SDF system, representing the first (elastic) mode of vibration of the structure.

\section{Description of pushover analysis}

The non-linear static pushover procedure was originally formulated and suggested by two agencies namely, federal emergency management agency (FEMA) and applied technical council (ATC), under their seismic rehabilitation programs and guidelines. This is included in the documents FEMA-273 [4], FEMA-356 [2] and ATC-40 [32].

\subsection{Introduction to FEMA-273}

The primary purpose of FEMA-273 [4] document is to provide technically sound and nationally acceptable guidelines for the seismic rehabilitation of buildings. The Guidelines for the Seismic Rehabilitation of Buildings are intended to serve as a ready tool for design professionals for carrying out the design and analysis of buildings, a reference document for building regulatory officials, and a foundation for the future development and implementation of building code provisions and standards.

\subsection{Introduction to ATC-40}

Seismic Evaluation and Retrofit of Concrete Buildings commonly referred to as ATC-40 [32] was developed by the Applied Technology Council (ATC) with funding from the California Safety Commission. Although the procedures recommended in this document are for concrete buildings, they are applicable to most building types.

\subsection{Pushover guideline as per ATC-40}

In Nonlinear Static Procedure, the basic demand and capacity parameter for the analysis is the lateral displacement of the building. The generation of a capacity curve (base shear v/s roof displacement) defines the capacity of the building uniquely for an assumed force distribution and displacement pattern. It is independent of any specific seismic shaking demand and replaces the base shear capacity of conventional design procedures. If the building displaces laterally, its response must lie on this capacity curve. A point on the curve defines a specific damage state for the structure, since the deformation for all components can be related to the global displacement of the structure. By correlating this capacity curve to the seismic demand generated by a specific earthquake or ground shaking intensity, a point can be found on the capacity curve that estimates the maximum displacement of the building the earthquake will cause. This defines the performance point or target displacement. The location of this performance point relative to the performance levels defined by the capacity curve indicates whether or not the performance objective is met.

Thus, for the Nonlinear Static Procedure, a static pushover analysis is performed using a nonlinear analysis program for an increasing monotonic lateral load pattern. An alternative is to perform a step by step analysis using a linear program. The base shear at each step is plotted again roof displacement. The performance point is found using the Capacity Spectrum Procedure. The individual structural components are checked against acceptability limits that depend on the global performance goals. The nature of the acceptability limits depends on specific components. Inelastic rotation is typically one of acceptability parameters for beam and column hinges. The limits on inelastic rotation are based on observation from tests and the collective judgment of the development team.

\section{Methodology}

The methods of pushover analysis used here capacity spectrum method and time history method 


\subsection{Inelastic component behavior}

The key step for the entire analysis is identification of the primary structural elements, which should be completely modeled in the non-linear analysis. Secondary elements, which do not significantly contribute to the building's lateral force resisting system, do not need to be included in the analysis. In concrete buildings, the effects of earthquake shaking are resisted by vertical frame elements or wall elements that are connected to horizontal elements (diaphragms) at the roof and floor levels. The structural elements may themselves comprise of an assembly of elements such as columns, beam, wall piers, wall spandrels etc. It is important to identify the failure mechanism for these primary structural elements and define their non-linear properties accordingly. The properties of interest of such elements are relationships between the forces (axial, bending and shear) and the corresponding inelastic displacements (displacements, rotations, drifts). Earthquakes usually load these elements in a cyclic manner as shown in Fig. 2. For modeling and analysis purposes, these relationships can be idealized as shown in Fig. 3 using a combination of empirical data, theoretical strength and strain compatibility.

\subsection{Capacity spectrum method}

One of the methods used to determine the performance point is the Capacity Spectrum Method, also known as the Acceleration-Displacement Response Spectra method (ADRS). The Capacity Spectrum method requires that both the capacity curve and the demand curve be represented in response spectral ordinates. It characterizes the seismic demand initially using a 5\% damped linear-elastic response spectrum and reduces the spectrum to reflect the effects of energy dissipation to estimate the inelastic displacement demand. The point at which the Capacity curve intersects the reduced demand curve represents the performance point at which capacity and demand are equal.

\subsection{Time history method}

Time-History Analysis shall be performed with no fewer than three data sets (two horizontal components or, if vertical motion is to be considered, two horizontal components and one vertical component) of appropriate ground motion time histories that shall be selected and scaled from no fewer than three recorded events. Appropriate time histories shall have magnitude, fault distances, and source mechanisms that are consistent with those that control the design earthquake ground motion. Where three appropriate recorded ground motion time history data sets are not available, appropriate simulated time history data sets may be used to make up the total number required. For each data set, the square root of the sum of the squares (SRSS) of the 5\%-damped site-specific spectrum of the scaled horizontal components shall be constructed. The data sets shall be scaled such that the average value of the SRSS spectra does not fall below 1.4 times the 5\%-damped spectrum for the design earthquake for periods between $0.2 T$ seconds and $1.5 T$ seconds (where $T$ is the fundamental period of the building). Where three time history data sets are used in the analysis of a structure, the maximum value of each response parameter (e.g., force in a member, displacement at a specific level) shall be used to determine design acceptability. Where seven or more time history data sets are employed, the average value of each response parameter may be used to determine design acceptability.

\subsection{Description of building}

\section{Analysis and result}

In the present work, a four storied reinforced concrete frame building situated in Zone IV, is taken for the purpose of study. The plan area of building is $10 \times 8 \mathrm{~m}$ with $3.5 \mathrm{~m}$ as height of each typical storey. It consists of 2 bays of $5 \mathrm{~m}$ each in X-direction and 2 bays of $4 \mathrm{~m}$ each in Y-direction. Hence, the building is symmetrical about both the axis. The total height of the building is $14 \mathrm{~m}$. The building is considered as a Special Moment resisting frame.

\subsection{Symmetrical building with shear wall}

Shear wall is modeled as shell element. Thickness of shear wall is taken equal to $130 \mathrm{~mm}$. As the building is symmetric shear wall is provided in one bay of building frame.

\subsection{Base force}

The base force for the four-storey building with different combination of element reinforcement at various floor levels. It is observed that with increase in reinforcement of beams only, there is a very minimal percentage change in the base force varying from $1.28 \%$ to $-3.27 \%$, which the structure can carry. However, with the increase in reinforcement of storey columns, there is quite an appreciable change in the base force carrying capacity of the structure. Further there is a decline of $4.63 \%$ in the base force capacity, when shear wall is provided in one bay of building frame. The combination of change of reinforcement in beams and columns both show a small increase in base force capacity.

Base shear decreases by $7.55 \%$ when shear wall is provided in one bay of structure. 


\subsection{Roof Displacement}

The Roof displacement for the four-storey building with different combination of element reinforcement at various floor level. It is observed that by increasing the reinforcement of beams only, there is a decrease in the roof displacement up to 3rd storey and after 3rd storey there is no change. The percentage change varies from $1.89 \%$ to $13.59 \%$. However, the trends shown by increasing the reinforcement of columns only is a substantial decrease in the roof displacement which varies from $0.6 \%$ to $21.08 \%$. The combination of increase of reinforcement of beams and columns both, show a little increase in the roof displacement up to 2nd storey and after 3rd storey it slightly decreases up to 4th storey.

There is a predominant decrease $(63.36 \%)$ in roof displacement when shear wall is provided in building.

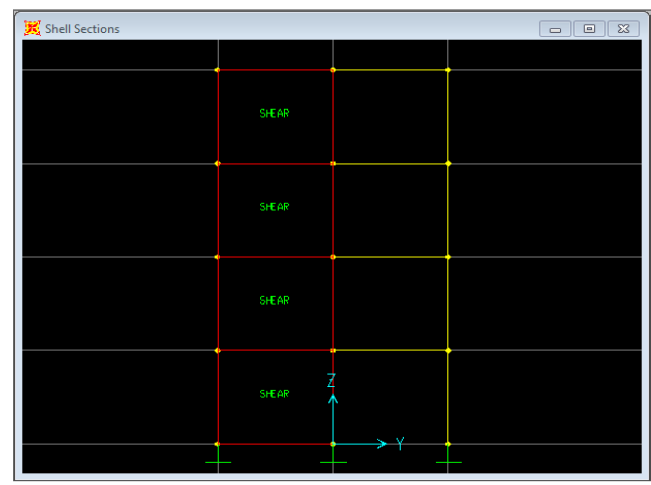

Fig. 1 Shear wall in symmetrical building

\subsection{Unsymmetrical building with shear wall}

Shear wall is modeled as shell element. Thickness of shear wall is taken equal to $130 \mathrm{~mm}$. The building is unsymmetrical and there are two case of providing shear wall.

1) Shear wall on along smaller side

2) Shear wall on along longer side

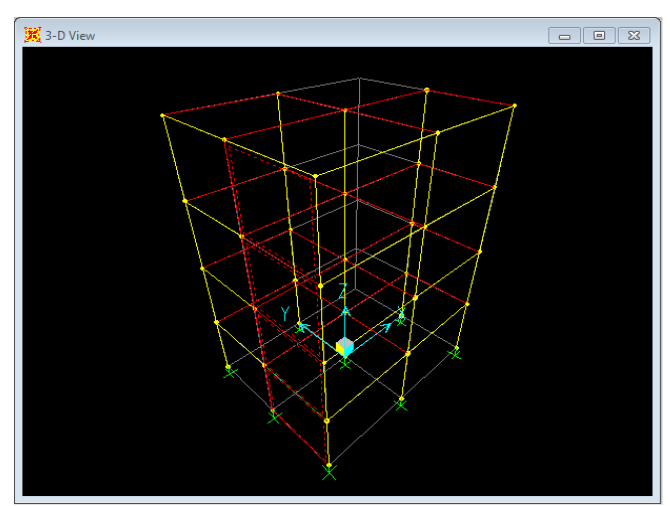

Fig.2 Shear wall along smaller side

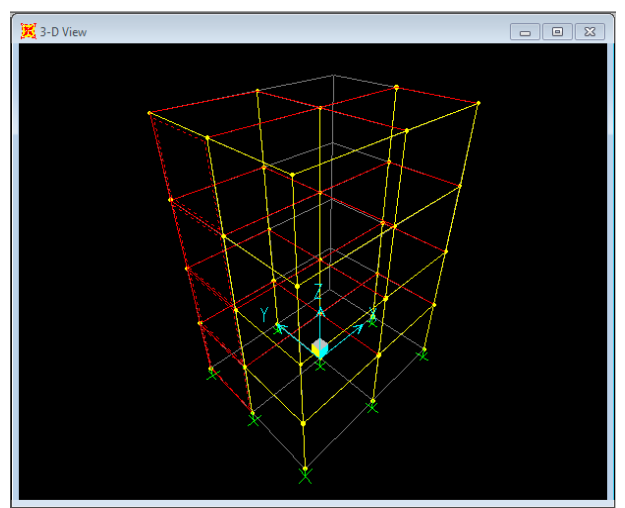

Fig.3 Shear wall on along longer side 


\subsection{Base force}

The base force for the four-storey building with different combination of element reinforcement at various floor levels.

It is observed that with increase in reinforcement of beams only, there is a nominal percentage change in the base force varying from $0.07 \%$ to $-8.46 \%$, which the structure can carry. However, with the increase in reinforcement of storey columns, there is quite an appreciable change in the base force carrying capacity of the structure. The combination of change of reinforcement in beams and columns both show a consistent increase in base force capacity.

Further there is a decline of $4.3 \%$ in the base force capacity, when shear wall is provided on the larger side of the building frame, whereas when it is provided on the smaller side there is a substantial decrease of $7.97 \%$

\subsection{Roof Displacement}

The Roof displacement for the four-storey building with different combination of element reinforcement at various floor levels. It is observed that by increasing the reinforcement of beams only, there is a decrease in the roof displacement up to 3rd storey and after 3rd storey there is no change. The percentage change varies from $11.39 \%$ to $42.66 \%$. However, the trends shown by increasing the reinforcement of columns only is a substantial increase in the roof displacement which varies from $9.09 \%$ to $30.01 \%$. The combination of increase of reinforcement of beams and columns both show a little increase in the roof displacement up to 2 nd storey and after 3rd storey it slightly decreases up to 4th storey.

There is a predominant decrease of $59.09 \%$ in roof displacement when shear wall is provided on the larger side of the building frame, whereas when it is provided on the smaller side the decrease is $58.92 \%$.

Table 1 Base and displacement decreases after providing shear wall

\begin{tabular}{|c|c|c|c|}
\hline \multirow[t]{2}{*}{ Element } & \multirow{2}{*}{$\begin{array}{l}\text { Symmetrical } \\
\text { building }\end{array}$} & \multicolumn{2}{|c|}{ Unsymmetrical building } \\
\hline & & $\begin{array}{l}\text { Shear } \\
\text { wall } \\
\text { larger } \\
\text { side }\end{array}$ & $\begin{array}{l}\text { Shear wall } \\
\text { Smaller } \\
\text { side }\end{array}$ \\
\hline Base shear & $7.55 \%$ & $7.97 \%$ & $4.3 \%$ \\
\hline $\begin{array}{l}\text { Roof } \\
\text { displacement }\end{array}$ & $63.36 \%$ & $55.4 \%$ & $58.15 \%$ \\
\hline
\end{tabular}

\section{Conclusion}

1) Provision of shear wall results in a huge decrease in base shear and roof displacement both symmetrical building and un-symmetrical building.

2) In L-shaped building when shear wall is provided on the larger side of the building results in a decrease of $4.3 \%$ in base shear and $58.15 \%$ in roof displacement and when provided on smaller side results in a decrease of $7.97 \%$ in base shear and $55.43 \%$ in roof displacement. Hence in unsymmetrical buildings shear wall must be provided on smaller side of building.

3) The performance based seismic design obtained by above procedure satisfies the acceptance criteria for immediate occupancy and life safety limit states for various intensities of earthquakes.

4) Performance based seismic design obtained leads to a small reduction in steel reinforcement when compared to code based seismic design (IS 1893:2002) obtained by STAAD.Pro.

\section{References}

[1]. ASCE, 1998, Handbook for the Seismic Evaluation of Buildings, a Prestandard, FEMA 310 Report, prepared by the American Society of Civil Engineers for the Federal Emergency Management Agency, Washington, D.C.

[2]. ASCE, 2000, Prestandard and Commentary for the Seismic Rehabilitation of Buildings, FEMA 356 Report, prepared by the American Society of Civil Engineers for the Federal Emergency Management Agency, Washington, D.C.

[3]. ASCE, 2002, Standard Methodology for Seismic Evaluation of Buildings. Standard No. ASCE-31. American Society of Civil Engineers, Reston, Virginia.

[4]. ATC, 1997a, NEHRP Guidelines for the Seismic Rehabilitation of Buildings, FEMA 273 Report, prepared by the Applied Technology Council for the Building Seismic Safety Council, published by the Federal Emergency Management Agency, Washington, D.C.

[5]. ATC, 1997b, NEHRP Commentary on the Guidelines for the Seismic Rehabilitation of Buildings, FEMA 274 Report, prepared by the Applied Technology Council, for the Building Seismic Safety Council, published by the Federal Emergency Management Agency, Washington, D.C.

[6]. ATC, 2006, Next-Generation Performance-Based Seismic Design Guidelines: Program Plan for New and Existing Buildings, FEMA 445, Federal Emergency Management Agency, Washington, D.C.

[7]. Bertero VV. 1997, Performance-based seismic engineering: a critical review of proposed guidelines. In: Proceedings of the International Workshop on Seismic Design Methodologies for the Next Generation of Codes. Bled/Slovenia.

[8]. Biggs JM. 1964 Book:- Introduction to structural dynamics. USA, Publisher: McGraw-Hill. 